\title{
Peertechz
}

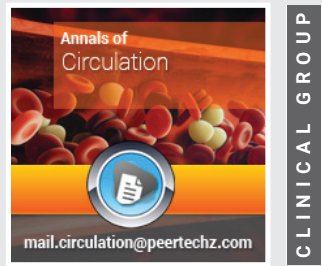

Review Article

\section{What is the best way to measure blood pressure?}

\section{Fernando Nobre* and Décio Mion Júnior}

Invited Professor, Medicine School of Ribeirão Preto, São Paulo University, Brazil
Received: 10 February, 2021

Accepted: 18 March, 2021

Published: 20 March, 2021

*Corresponding author: Fernando Nobre, MD, PhD, FESC, FACC, Invited Professor, Medicine School of Ribeirão Preto, São Paulo University, Brazil, Fax: +55 16 3620 2020; E-mail: fernando.nobre@uol.com.br https://www.peertechzpublications.com
Since Scipiano Riva-Rocci [1] created the device to measure Blood Pressure (BP), more than a century has passed with gains in knowledge of this way of assessing BP.

Currently, the methods for assessing blood pressure in the 24 hours using devices capable of making these records are well established [2].

Hypertension is frequently diagnosed using office Blood Pressure (BP) measurements. However, recent guidelines strongly recommend out-of-office BP monitoring (including Ambulatory BP Monitoring (ABPM) for the diagnosis and management of Hypertension [3-6].

Due to limitations in office measures, since the 1960s, six decades after the creation of the first device capable of measuring during the daily activities of patients (Figure 1), identified as ABPM, this form of blood pressure recording has been gaining prominence and proving to be able to represent the real behavior of blood pressure assessed for a period of 24 hours.

With the natural evolution of technology, ABPM equipment became lighter, lower-noise and more comfortable.

The limitations to its use, due to possible discomfort during its performance, frequently referred to in the literature, were not confirmed in a study conducted by Nobre, et al. [7] (Figure 2).

With the advent of ABPM, it was possible to identify phenotypes previously unknown, such as: white coat hypertension and masked hypertension [8].

Based on the blood pressure record for 24 hours, outside the office, today we can consider the classification of blood pressure behavior as shown in Figure 3.

Thus, what in the past was only the classification of individuals, based on office measures, normotensive and hypertensive, we now have two other situations where

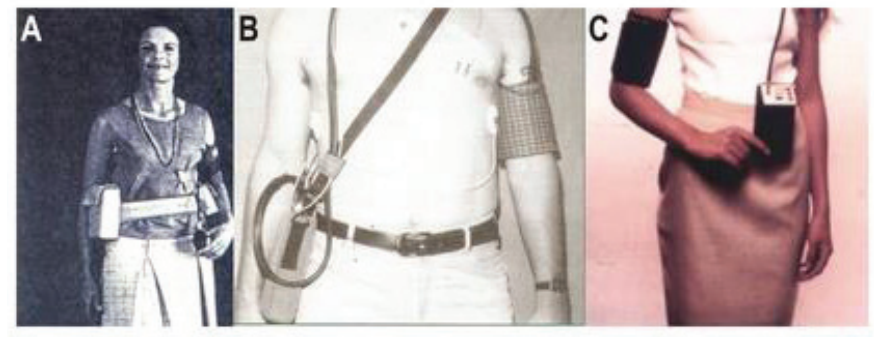

Figure 1: Evolution of devices to measure ambulatory pressure from 1966 to 2021. (From Left to Right: $A=1966 ; B=1988$ and $C=2021$ ). Personal file of the authors.

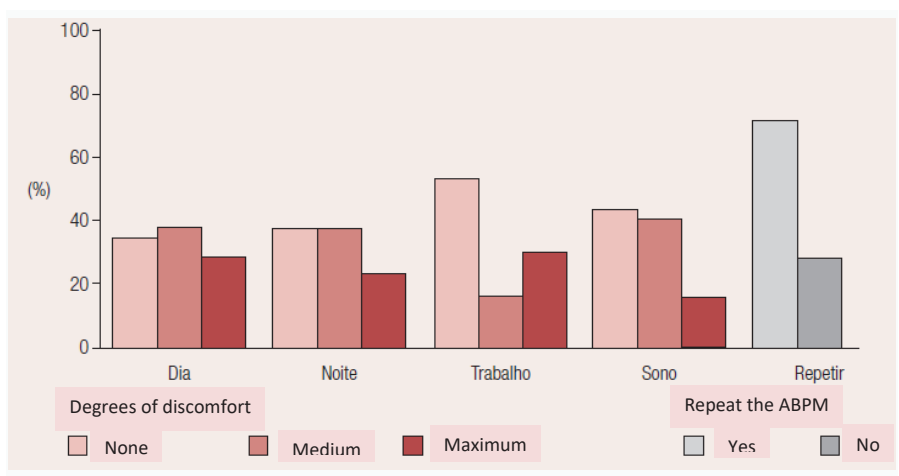

Figure 2: Degrees of discomfort with Ambulatory Blood Pressure Monitoring [7].

the behavior of blood pressure is systematically changed $(\geq 140 \times 90 \mathrm{~mm} \mathrm{Hg})$ in the office whereas in the mean of the $24^{-}$ hour period by ABPM the values are normal $(<130 \times 80 \mathrm{~mm} \mathrm{Hg})$ and another group characterized by always normal behavior in office measurements $(<140 \times 90 \mathrm{~mm} \mathrm{Hg})$ and altered in ABPM $(\geq$ $130 \times 80 \mathrm{~mm} \mathrm{Hg})$.

Sustained hypertension, normotension, white coat hypertension and masked hypertension: Definitions and prevalences

Susteined hypertension was a conventional blood pressure 
of $140 \mathrm{~mm} \mathrm{Hg}$ systolic or $90 \mathrm{~mm} \mathrm{Hg}$ diastolic or more. Ambulatory hypertension was a 24 -hour level of $130 \mathrm{~mm} \mathrm{Hg}$ systolic or $80 \mathrm{~mm} \mathrm{Hg}$ diastolic or more; for the daytime blood pressure these thresholds were 135 and $85 \mathrm{~mm} \mathrm{Hg}$ and for the nighttime blood pressure 120 and $70 \mathrm{~mm} \mathrm{Hg}$, respectively [9]. Normotension and sustained hypertension were consistently normal or elevated levels on both conventional and ambulatory blood pressures. White-coat hypertension was defined as conventional hypertension in the presence of a normal ambulatory blood pressure. Masked hypertension was defined as ambulatory hypertension in participants with a normal conventional blood pressure. When systolic or diastolic blood pressure was in a different category (normotensive versus hypertensive), we considered the participant as hypertensive.

\section{Prevalences of the four main phenotypes characterizing different blood pressure behaviors}

According Key Assayama, et al. (IDACO study) [10], based on the cross-classification between conventional and 24-hour ambulatory blood pressure $60.6 \%$ were normotensive: $10,7 \%$ had white coat hypertensions; $9,7 \%$ had maskad hyperension and, final $19 \%$ had susteined hypertension. Using different time intervals during which ambulatory blood pressure thresholds were applied substantially affected the estimates of prevalence. They ranged from $50.7 \%$ to $60.6 \%$ for normotension, from $6.3 \%$ to $12.5 \%$ for white-coat hypertension, from $9.7 \%$ to $19.6 \%$ for masked hypertension, and from $17.3 \%$ to $23.5 \%$ for sustained hypertension. The prevalence of normotension and white-coat hypertension was lowest and the prevalence of masked and sustained hypertension was highest based on thresholds set simultaneously to the 24 -hour and the daytime and nighttime blood pressures).

Folowing, we will consider the prognosis and behaviors indicated for the two main phenotypes: White coat hypertension and masked hypertension.

Normotension, sustained hypertension, white coat hypertension, and masked hypertension: Prognosis and conduct

According to Hansen TW [11], the prognosis of the White Coat Hypertension and Masked Hypertension can be seen in the Figures 4,5.

The therapeutic approach of these various phenotypes is well studied. Particular emphasis should be placed on two of them: White Coat Hypertension and Masked Hypertension.

\section{White coat hypertension}

There is no evidence of the benefits of interventions in this group of patients [12,13]. These patients need followup, and changes in lifestyle are imperative for everyone. It is recommended that the diagnosis of white coat hypertension be confirmed in 3 to 6 months, and the patient be followed annually with ABPM to detect progression to maintained hypertension, as these patients are more likely to become established hypertensive [14].

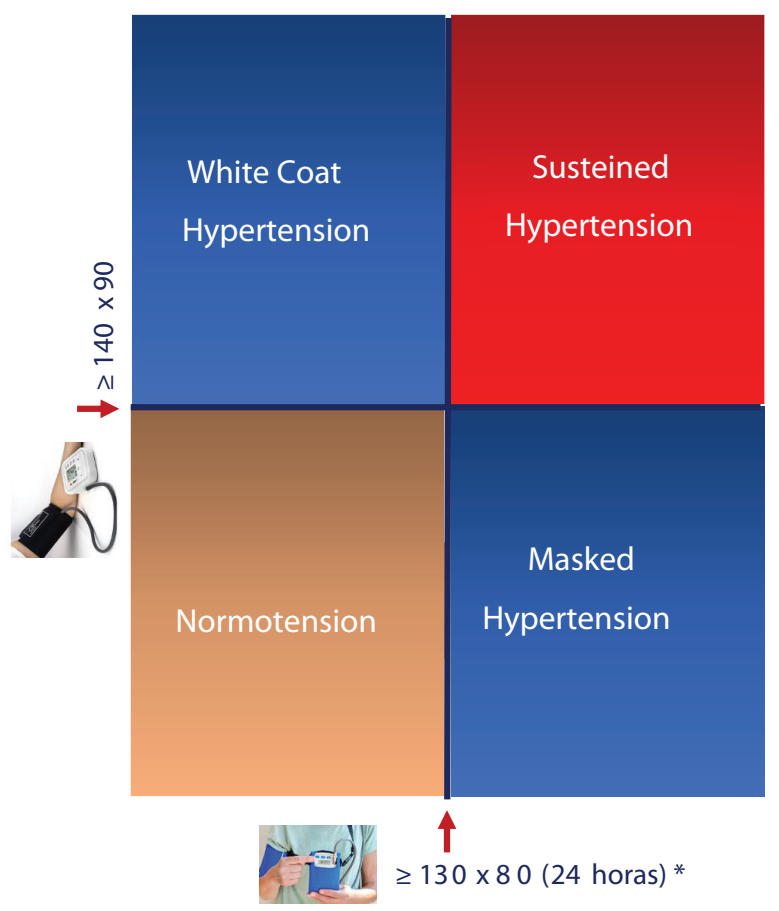

Figure 3: Classification of blood pressure behavior with the advent of ABPM (* or Wake $\geq 135 \times 85 \mathrm{~mm} \mathrm{Hg}$ and sleep $\geq 120 \times 70 \mathrm{~mm} \mathrm{Hg}$ ).

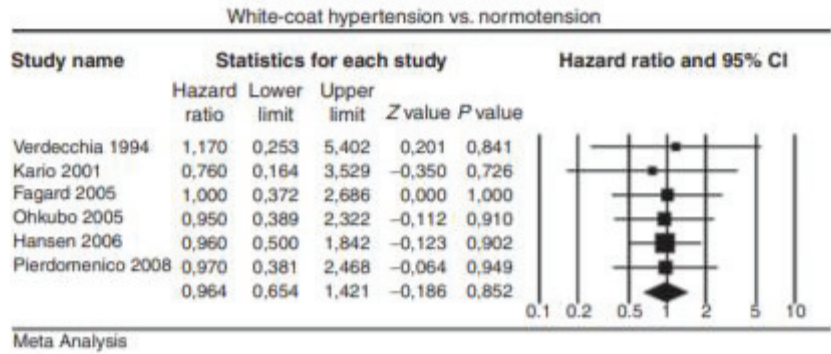

Figure 4: Adjusted hazar ratio (HR) and 95\% confidence interval (Cl) for the incidence of events between subjects with White Coat Hypertension and Normotension. For Hansen, et al. [11] HR and $\mathrm{Cl}$ are update data provide by the authors and for the other studies are published data.

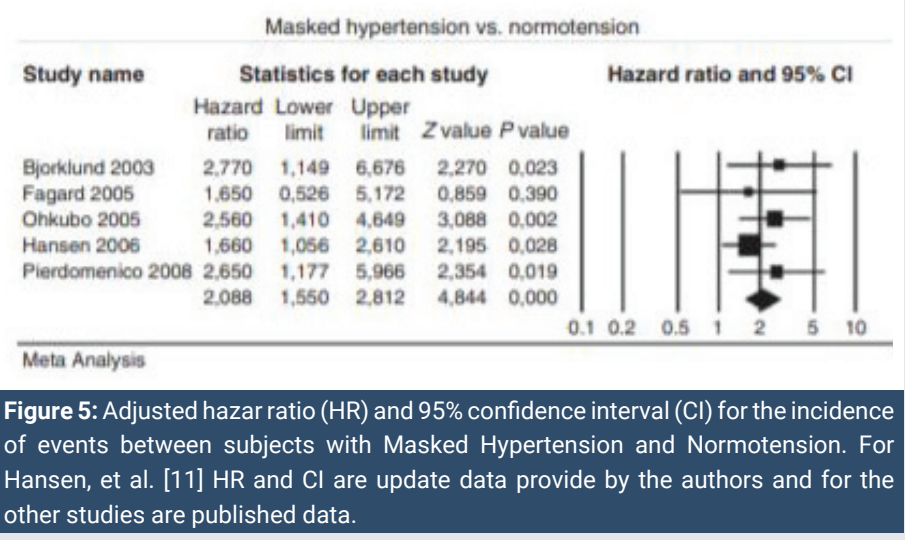

To our knowledge, there is currently no evidence from randomized clinical trials testing whether lowering versus not lowering office BP in white-coat hypertensive might result in benefit [14]. Lifestyle changes are consensual in these patients with white coat hypertension. 


\section{Masked hypertension}

In view of the high-risk profile associated with masked hypertension, the 2017 American College of Cardiology/ American Heart Association [3] and the 2018 European [15] hypertension guidelines consistently recommend that masked hypertensive patients should implement lifestyle interventions and be treated with antihypertensive drugs. However, in the absence of supporting evidence from randomized clinical trials, this recommendation rests largely on expert opinion [13].

\section{Conclusions and perspectives}

With the advent of the 24-hour ABPM, a blood pressure record was able to more accurately reflect the behavior of blood pressure for the purpose of diagnosis, prognosis and evaluation of the antihypertensive therapy instituted.

In addition, there was the possibility of defining new blood pressure phenotypes such as: white coat hypertension and masked hypertension.

White coat hypertension and masked hypertension have not been identified as benign conditions and the data currently available recommend specific care for the patient populations that fall into these two groups, as much as the diagnosis, as well as the assessment of prognosis and treatment.

Several and recent publications [16-19] have confirmed the importance of measures taken during a day of usual activities of patients, by ABPM. Thus, this method has been gradually gaining a prominent place in medical practice.

In the near future, with the expansion of that used by MAPA, the existing knowledge will be consolidated and new studies will complete the gaps that exist today.

Anyway, we can assure that ABPM, in relation to blood pressure measurement, brought more light and less shadows.

\section{References}

1. Riva-Rocci S (1896) Um nuovo sfigmomanometro. Gazz Med Torino 47: 9811001. Link: http://bit.ly/3bYdbOH

2. Omboni S, Palatini P, Parati G (2015) Working Group on Blood Pressure Monitoring of the Italian Society of Hypertension. Standards for ambulatory blood pressure monitoring clinical reporting in daily practice: recommendations from the Italian Society of Hypertension. Blood Press Monit 20: 241-244. Link: https://bit.ly/38WAFBi

3. Whelton PK, Carey RM, Aronow WS, Casey DE, Collins KJ, et al. (2017) ACC/ AHA/AAPA/ABC/ACPM/AGS/APhA/ASH/ASPC/NMA/PCNA Guideline for the Prevention, Detection, Evaluation, and Management of High Blood Pressure in Adults: A Report of the American College of Cardiology/American Heart Association Task Force on Clinical Practice Guidelines. Hypertension 71: e13-e115. Link: http://bit.ly/2PaNRvf

4. Siu AL, Force USPST (2015) Screening for high blood pressure in adults: U.S Preventive Services Task Force recommendation statement. Ann Intern Med 163: 778-786. Link: http://bit.ly/3eS7vHv
5. Muntner P, Shimbo D, Carey RM, Charleston JB, Gaillard T, et al. (2019) Measurement of Blood Pressure in Humans: A Scientific Statement From the American Heart Association. Hypertension 73: e35-e66. Link: http://bit.ly/2Pbwv1i

6. Nobre F, Mion Júnior D, Gomes MAM (2018) VI Diretriz Brasileira de MAPA e MRPA Arq Bras Cardiol 110: 1-29.

7. Lima NKC, Santos LAC, Brega AG, Mion Jr. Décio, Nobre F (1998) Acceptance and Tolerability to Ambulatory Blood Pressure Monitoring. J Hypertension 16 : S270.

8. Nobre F, Mion D (2016) Ambulatory Blood Pressure Monitoring: Five Decades of More Light and Less Shadows. Arq Bras Cardiol 106: 528-537. Link: http://bit.ly/3cPoWpu

9. Mancia G, Fagard R, Narkiewicz K, Redon J, Zanchetti A, et al. (2013) ESH/ ESC guidelines for the management of arterial hypertension: the Task Force for the Management of Arterial Hypertension of the European Society of Hypertension (ESH) and of the European Society of Cardiology (ESC). Eur Heart J 34: 2159-2219. Link: https://bit.ly/3bZxwCB

10. Yang WY, Melgarejo JD, Thijs L, Zhang ZY, Boggia J, et al. (2019) Association of Office and Ambulatory Blood Pressure With Mortality and Cardiovascular Outcomes. JAMA 322: 409-420. Link: http://bit.ly/2Pbxfn6

11. Hansen TW, Jeppesen J, Rasmussen S, Ibsen H, Torp-Pedersen C (2006) Ambulatory blood pressure monitoring and risk of cardiovascular disease: a population based study. Am J Hypertens 19: 243-250. Link: http://bit.ly/3eYZAli

12. Franklin SS, Thijs L, Hansen TW, O'Brien E, Staessen JA (2013) White-coat hypertension: new insights from recent studies. Hypertension 62: 982-987. Link: http://bit.ly/3vBxPM1

13. Huang QF, Yang WY, Asayama K, Asayama K, Thijs L, et al. (2021) Staessen Ambulatory Blood Pressure Monitoring to Diagnose and Manage Hypertension. Hypertension 77: 254-264. Link: http://bit.ly/31aVjtr

14. O’Brien E, Parati G, Stergiou G, Asmar R, Beilin L, Bilo G, et al. (2013) European Society of Hypertension Working Group on Blood Pressure Monitoring. European Society of Hypertension position paper on ambulatory blood pressure monitoring. J Hypertens 31: 1731-1768. Link: http://bit.ly/3c15iHV

15. Williams B, Mancia G, Spiering W, Agabiti Rosei E, Azizi M, et al. (2018) ESC Scientific Document Group. 2018 ESC/ESH Guidelines for the management of arterial hypertension. Eur Heart J 39: 3021-3104. Link: http://bit.ly/3qV8N6U

16. Ghazi L, Pajewski NM, Rifkin DE, Bates JT, Chang TI, et al. (2019) Effect of Intensive and Standard Clinic-Based Hypertension Management on the Concordance Between Clinic and Ambulatory Blood Pressure and Blood Pressure Variability in SPRINT. Effect of Intensive and Standard ClinicBased Hypertension Management on the Concordance Between Clinic and Ambulatory Blood Pressure and Blood Pressure Variability in SPRINT. J Am Heart Assoc 8: e011706. Link: http://bit.ly/3cPqj7C

17. Muntner P, Einhorn PT, Cushman WC, Whelton PK, Bello NA, et al. (2019) Blood Pressure Assessment in Adults in Clinical Practice and Clinic Based Research: JACC Scientific Expert Panel. J Am Coll Cardiol 73: 317-335. Link: http://bit.ly/3cMOpQm

18. Stergiou GS, Palatini P, Parati G, O’Brien E, Januszewicz A, et al. (2021) European Society of Hypertension practice guidelines for office and out-of-office blood pressure measurement. J Hypertens 39. Link: http://bit.ly/3eVLOGw

19. Huang QF, Yang WY, Asayama K, Asayama K, Thijs L, et al. (2021) Staessen Ambulatory Blood Pressure Monitoring to Diagnose and Manage Hypertension. Hypertension 77: 254-264. Link: http://bit.ly/31aVjtr

Copyright: ( 2021 Nobre F, et al. This is an open-access article distributed under the terms of the Creative Commons Attribution License, which permits unrestricted use distribution, and reproduction in any medium, provided the original author and source are credited. 